\title{
Relative Value
}

National Cancer Institute

\section{Source}

National Cancer Institute. Relative Value. NCI Thesaurus. Code C45830.

Considered in comparison with something else; dependent on or interconnected with something else; not absolute. 